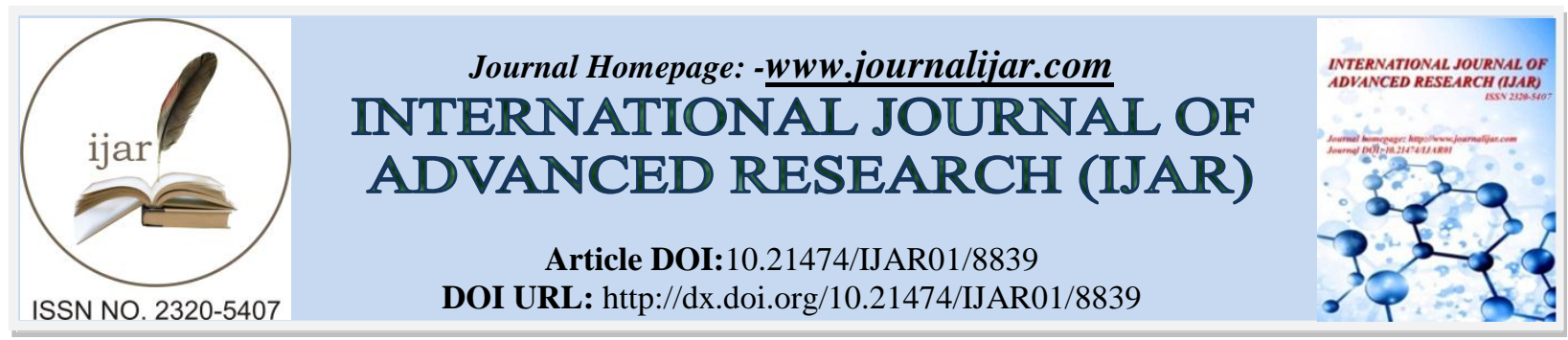

RESEARCH ARTICLE

\title{
LIBRARY 2.0: THE APPLICATION OF WEB 2.0 TECHNOLOGY TO LIBRARY AND INFORMATION SERVICES.
}

Swapan Kumar Bera ${ }^{1}$, Dr. Arun Modak² And Dr. Asitabha Das ${ }^{3}$.

1. Librarian, Baruipur College, P.O.- Purandarpur Math, Baruipur, Dist.-24Pgs (S), West Bengal and Ph. D Research Scholar of Sri Satya Sai University of Technology \& Medical Sciences, Shehore, Bhopal (MP).

2. Associate Professor \& HOD,Department of Library and Information Science,Sri Satya Sai University of Technology \& Medical Sciences, Shehore, Bhopal (MP).

3. University Librarian,Central Library, University of Kalyani, Dist.-Nadia, West Bengal.

\section{Manuscript Info}

\section{Manuscript History}

Received: 07 February 2019

Final Accepted: 09 March 2019

Published: April 2019

Key words:-

Blog, Library 2.0, Mash-up, Social network, Streaming media, Tagging, RSS, Web 2.0, Wiki.

\section{Abstract}

The implication of Web 2.0 technologies to libraries and information centres resulted in the coining of the term Library 2.0. This paper aims at seeking the use of Web 2.0 applications by the library and information professionals. Library 2.0 is a concept for different library and information services. This article suggests that recent thinking describing the changing ' $\mathrm{Web}$ ' as 'Web 2.0' will have substantial implications for libraries. The paper discusses the theory and definition to the practice of librarianship, specifically addressing how the technology Web 2.0 such as synchronous messaging and streaming media, blogs, wikis, social networks, tagging, RSS feeds library thing, podcasts, YouTube, Second Life and mash-ups might intimate changes in how libraries provide access to their collections and user support for that access. Conclusion stated that the implementation of Web 2.0 technologies in libraries is very much fruitful to cope with the changing paradigm.

Copy Right, IJAR, 2019,. All rights reserved.

\section{Introduction:-}

The traditional library and information services used the technology as only extensions of their existing manual operations. Library 2.0 is a new concept where users are not only consumers but also content creators. Library 2.0 is a library with fullest participation of users as architects and without any boundaries. Simply library 2.0 is the implication of web 2.0 technologies to library and information services. To know application of library 2.0 , it is very much needful to know about web 2.0. Web 2.0 has human aspects of interactivity.

\section{Web 2.0 :}

Tim O'Reilly is the pioneer of web 2.0 theory. According to O'Reilly(2005), "Web 2.0 is the network as platform, spanning all connected devices; Web 2.0 applications are those that make the most of the intrinsic merits of that platform: delivering software as a continually-updated service that gets better the more people use it, consuming and remixing data from multiple sources, including individual users, while providing their own data and services in a form that allows remixing by others, creating network effects through an "architecture of participation," and going beyond the page metaphor of Web 1.0 to deliver rich user experiences. Web 2.0 is not a web of textual publication, 
but a web of multi-sensory communication. It is a matrix of dialogues (Maness, 2006). Web 2.0 is a trend in WWW technology, and web design, a second generation of web based communities and hosted services which aim to facilitate creativity, collaboration and sharing among them (wikipedia).

\section{Characteristics of Web 2.0:}

The important features of web 2.0 are as follows:

1. Web 2.0 is participative. It permits the users to actively participate online by means of blogging, sharing files.

2. It allows the building virtual applications.

3. It permits data to be exposed, discovered and manipulated.

4. It is built upon belief and trust.

5. It is smart.

6. Web 2.0 applications are modular.

7. Web 2.0 is about sharing.

\section{WEB as Platform:}

Web 2.0 doesn't have a hard boundary, but rather, a gravitational core. We can visualize Web 2.0 as a set of principles and practices that combine together a veritable solar system of sites that demonstrate some or all of those rules and regulations, at a varying distance from that core.

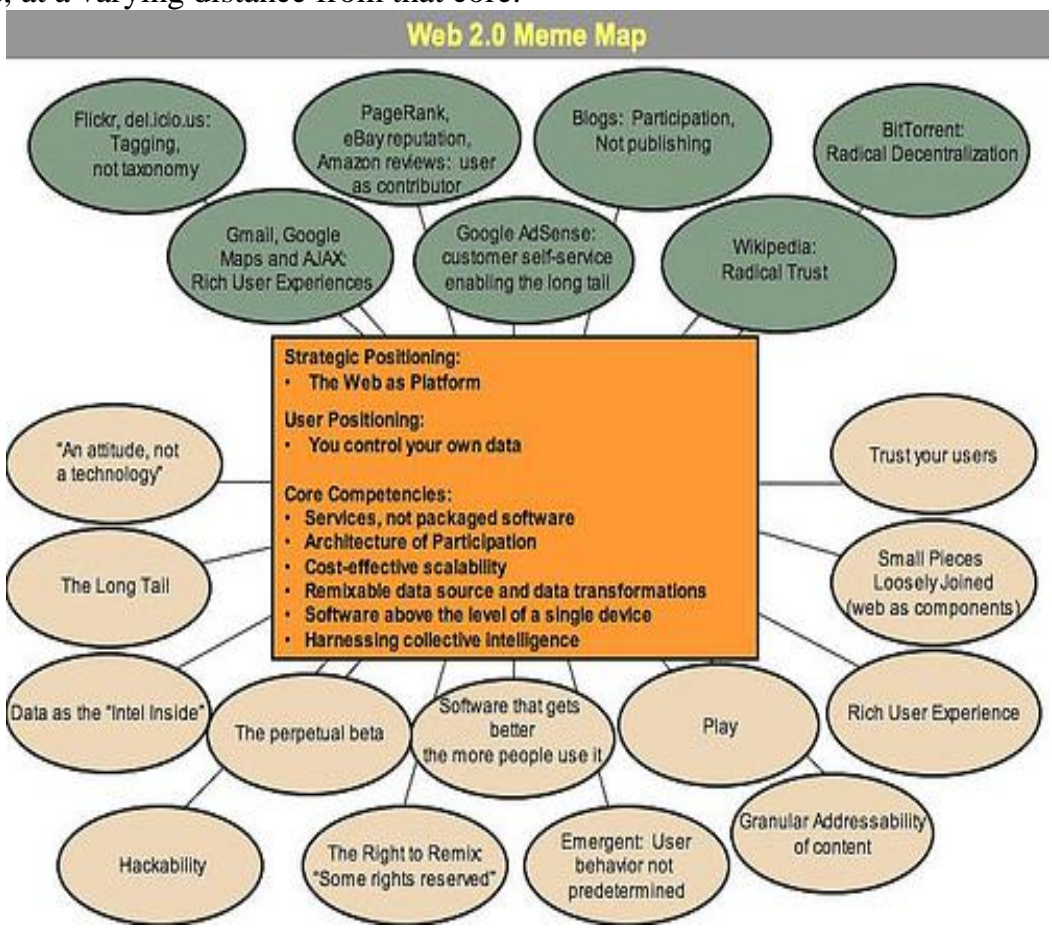

Figure1:-Web 2.0 Meme Map

Figure 1 shows a "meme map" of Web 2.0 that was developed at a brainstorming session during FOO Camp, a conference at O'Reilly Media. The basic principle of web 2.0 was the web as the platform.

Table 1:-Web 1.0 Vs Web 2.0

\begin{tabular}{|l|l|}
\hline \multicolumn{1}{|c|}{ Web 1.0 } & Web 2.0 \\
\hline Akamai & BitTorrent \\
\hline Britannica Online & Wikipedia \\
\hline Content management systems & Wikis \\
\hline Domain name speculation & Search engine optimization \\
\hline DoubleClick & Google AdSense \\
\hline Ofoto & Flickr \\
\hline Mp3.com & Napster \\
\hline
\end{tabular}




\begin{tabular}{|l|l|}
\hline Personal websites & Blogging \\
\hline Evite & Upcoming.org and EVDB \\
\hline Page views & Cost per click \\
\hline Screen scrapping & Web services \\
\hline Publishing & Participation \\
\hline Directories(taxonomy) & Tagging(“folksonomy") \\
\hline Stickiness & Syndication \\
\hline
\end{tabular}

Table 1 shows the web 2.0 services as compared with web 1.0.

Each of the technologies listed in Web 2.0 above - blogging, RSS, Wikis, personalization, streaming media, ratings, alerts, tagging, social networking software, folksonomies, and the rest could be useful in an enterprise, institutional, or community environment and could be driven or introduced by the library and information centres.

Components of Web 2.0:

Components of web 2.0 may be grouped into four categories. They are as follows:

\section{Social networking component:}

It includes tools such as discussion forum, instant messaging, event listing, Flickr, Jumpcut, etc. These tools are increasing online socialization through community oriented communication and interaction.

\section{Read/Write Web component:}

Web 1.0 supports static contents and unidirectional flow of information but Web 2.0 supports dynamic contents. Itincludes the tools such as blogs, RSS, MySpace, Facebook, YouTube, Podcasts, etc.

\section{Collective intelligence support component:}

It includes tools such as Wikis, Wikipedias, LibraryThing, PaperBackSwap Second Life, Digg, Technorati, Folksonomy, Social bookmarking, Amazon services.

\section{Information Mashups component:}

Information mashups is a central idea of Web 2.0. These tools permit remixing of data, services or technologies from different online sources to create new hybrid services through lightweight application programming interface (API). Tools and services such as WikiBios, Library Lookup, Go-Go-Google Gadget etc.

\section{Information resources and Services of Web 2.0:}

The new brand of information resources and services of web 2.0 are as follows -

Blogs:

Blog is short form of web log--an online journal where information is posted on a regular basis and appears in reverse chronological order. It is a web site that is frequently updated. It can be authored by an individual or a team. Blogs are popular because user can create, update and publish information on a blog from any computer that is connected to the internet. Free web blog software is available such as Blog city, Radio user-land etc.

\section{Digg:}

It is an interactive news site where users submit and decide what stories are shown. The users can then click on the digg button attached to the story to indicate their likeness of like the story.

\section{Flickr:}

It is a photo sharing service which permits users to share, upload, comment on, and categorize photographs. Using "tags" or keywords the users can label photographs.

\section{Instant messaging:}

It permits real-time text communication between individuals.

\section{Jumpcut:}

Jumpcut allows users to access free editing tools that allow them edit, upload, remix and publish video footage. 


\section{Library thing:}

It admits users to prepare catalogue their reading materials and share lists with each other. Library professionals and patrons can thereby interact and recommend their resources to each other. Members can see book cover images, comment, recommend and review books, form special interest groups. The professionals can enter DDC number, rearrange books on virtual shelves, and add star rating of books.

\section{Mashups:}

These are applications that can take data from more than one online source and combine it to create new hybrid services unintended by the original content owners.

\section{MySpace and Facebook:}

They permit users to set up interactive and personalized web profiles detailing personal information like age, education, interests, and hobbies. Users are able to upload videos, photographs and music; create a blog, post comments on other user profile pages, and send messages to other users.

\section{Podcast:}

Podcasting is simply making audio files (most commonly in MP3 format) available online so that users can then download them to their desktop media player.

\section{RSS feed:}

RSS (Really Simple Syndication) permits users (after subscribing) to receive any new content added by a website, thus avoiding the necessity of continually visiting sites to check for updates.

\section{Second Life:}

It is one kind of subscription based virtual world where registered users interact by building, working, playing, and flying alongside other virtual characters.

\section{Social Bookmarking:}

It is a method for internet users to store, organize, search and manage bookmarks of web pages on the internet with the help of metadata. The bookmarks are usually public and can be saved privately, shared only with specified people or groups, shared only inside certain networks.

\section{Tags and Folksonomies:}

It is the name given to a collection of tags, effectively a "bottom-up" user generated taxonomy as opposed to an authoritative top down hierarchical taxonomy e.g., LC Subject Headings.

\section{Technorati:}

A site which is helpful for searching facility and clearinghouse for all things blog.

\section{Wikis:}

A software that allows users to easily edit, create, and link pages together. These are frequently used to create collaborative websites and to power community websites. Theses wiki websites are often referred to as wikis. Wikis are ideal for specific projects and collaborative knowledge sharing.

\section{YouTube:}

It admits users to tag, watch, upload, rate, review, view, and blog video outage, and even creates play lists.

\section{Library 2.0}

The term "Library 2.0" was opined by Michael Casey (2005) in his blog to denote implication of Web 2.0 and possible changes in Web-enabled library services. Some definitions of Library 2.0, given by experts are given below:

1. "Library 2.0 is the application of interactive, collaborative, and multi-media web-based technologies to webbased library services and collections" (Maness, 2006).

2. "Library 2.0 is very much influenced by technology-driven, two-way, social interactions between staff and staff or staff and patrons. L2 has provided a framework within which we've been able to re-evaluate virtually every aspect of classical librarianship with the end goal of usability and find-ability in mind" (Stephens, 2006). 
3. "Library 2.0 describes a subset of library services designed to meet user needs caused by the direct and peripheral effects of Web 2.0" (Habib, 2006).

\section{Library 2.0 has four essential elements. They are as follows:}

1. It is user-centered. Users can participate in the creation of the content and services which are within the library's web-presence, OPAC, etc. The consumption and creation of content is dynamic, and thus the roles of librarian and user are not always clear.

2. It provides a multi-media experience. Both the collections and services of Library 2.0 contain video and audio components. While this is not often cited as a function of Library 2.0, it is here suggested that it should be.

3. It is socially rich. The library's web-presence includes users' presences. There are both synchronous (e.g. IM) and asynchronous (e.g. wikis) ways for users to communicate with one another and with librarians.

4. It is communally innovative. This is perhaps the single most important aspect of Library 2.0. It rides on the foundation of libraries as a community service, but understands that as communities change, libraries must not only change with them, they must allow users to change the library. It seeks to continually change its services, to find new ways to allow communities, not just individuals to seek, find, and utilize information.

\section{Library 1.0 Vs Library 2.0}

In the terms of library and information services, it can be compared the Library 1.0 with Library 2.0 as follows:

Table 2:-Library1.0 Vs Library 2.0

\begin{tabular}{|l|l|}
\hline \multicolumn{1}{|c|}{ Library 1.0 } & \multicolumn{1}{c|}{ Library 2.0 } \\
\hline "Read-only" catalog & Amazon-style comments \\
\hline Closed stacks & Open stacks \\
\hline Collection development & Library suggestion box \\
\hline Preorganized ILS(Integrated Library Services) & User tagging \\
\hline Walk-in services & Globally available services \\
\hline Easy = dumb users & Easy = smart systems \\
\hline Limited service options & Broad range of options \\
\hline Print newsletter mailed out & Team-built blog \\
\hline Monolithic applications & Flexible, adaptive modules \\
\hline Information as commodity & Information as conversation \\
\hline Mission focus is output & Mission focus is outcome \\
\hline ILS is core operation & User services are core \\
\hline
\end{tabular}

Application of Web 2.0 tools in Library 2.0:

Libraries and information centres which are in comfortable position may apply Web 2.0 concepts. But a set of Web 2.0 tools cannot be recommended for all kinds of libraries and information centres. A few potential, free/open Web 2.0 tools for applications in library services are given as follows:

\section{e-Blogger:}

It is the tool that provide a free way to set up blog. It currently allows access using a Google account, and makes setting up a blog an easy task. Fundamental posting is also very simple.

Flickr:

It is a image-sharing utility that permits users to resize, organize, upload and share digital photos or images. The basic membership is free and there are several different ways to upload photos. Flickr provides online help and other organizational functions that are very user-friendly

\section{Facebook:}

It is a social networking site that tends to be used by the young population. Although originally available only to young adults, Facebook opened membership to anyone with a valid e-mail address in 2006 . The site is organized by "networks," where each user can create a profile with information about them and invite other users to be their "friends." In addition to sharing access to a profile, a user can share photos, websites, and invitations to upcoming events. 


\section{Del.icio.us:}

This tool allows saving a group of links in one place. The interface and setup are quite user friendly and some Web browser (e.g. Mozila Firefox) are delicious ready. The uses of del.icio.us include the ability to access favourite sites by users (without having to remember the URLs) from any computer. The abilities to share these bookmarks with others, and the possibility of finding other websites (marked as useful by delicious users) are most visible utilities of social bookmarking

\section{LibraryThing:}

It is a very useful tool for librarians. This site allows creating personal library catalog, searching for reading materials using Amazon or other library catalogues; tags books with user-driven descriptors, and helps to share library resources with others. Apart from these utilities, it provides web 2.0 features such as changing a catalog record, tagging records, and joining a group.

\section{MySpace:}

MySpace is very popular in the community of teenagers. Fundamental knowledge of HTML is necessary to make a MySpace page attractive and informative. However, if library professionals are trying to reach a younger target audience, it may help them to perform many outreach activities.

\section{Ning:}

This is a social networking site like MySpace and Facebook, but works differently. It allows users to create their own networks. Some examples of networks on Ning include the Open Coffee Club, Classroom 2.0, and Whales, etc. There are a good number of networks which are related to library and information science. In the library and information services, this tool may be useful in allowing groups to create online space for group interaction.

\section{Second Life:}

It is a virtual world where users can become residents, make avatars, attend events, buy land, and create virtual objects. Second Life users interact in real time. While a basic account is free and allows a person to create an avatar, most of the higher-level activities, such as buying land and building objects, require a paid membership. Many libraries and information centres are using Second Life in creating virtual reading room service.

\section{Conclusion:-}

Web 2.0 is not mere a technology or a thing but a state of mind where the system or the service-platform empowers the users to input their opinion. Library 2.0 put great challenges before the librarian to redefine their traditional services and approach. Librarian 2.0 will be the pathfinder of the information age and continuously strives to understand, learn and implement the library 2.0 functionalities. In this regards, the LIS professionals are responsible to connect people and technology for effective use of information. He doesn't shy away from non-traditional cataloguing and classification. He must choose tagging, tag clouds, folksonomies, and user-driven content descriptions and classifications where appropriate. He connects the users to expert discussions, conversations, and communities of practice and participates there as well and uses the latest tools of communication (such as Skype) to expertise, connect content, information coaching. He encourages user driven metadata and user developed content and commentary and understands the wisdom of crowds and the emerging roles and impacts of the blogosphere, Web syndicasphere and wikisphere. However, implementation of Web 2.0 technologies in library and information centres are very much fruitful to cope with the changing paradigm.

\section{References:-}

1. Casey, M. (2006a). Born in the biblioblogosphere. LibraryCrunch. Retrieved on 24.12.2018 from http://www.librarycrunch.com.

2. Habib, M. (2006). Conceptual model for academic library 2.0. Michael Habib's weblog on library and information science. Retrieved on 26.12.2018 fromhttp://mchabib.blogspot.com

3. <http:// Del.icio.us> retrieved on 26.12.2018

4. Maness, J. (2006). Library 2.0 Theory: Web 2.0 and Its Implications for Libraries. Webology, 3 (2), Article 25,. Retrieved on 26.12.2018

5. O'Reilly, T. (2005b). What is Web 2.0?Retrieved from http://www.oreilly.com/go/web2. Date- 27.12.2018

6. <www.wikipedia.com> retrieved on 27.12.2018. 